\title{
Química mineral e condições de cristalização do plutão ediacarano Bom Jardim de Goiás, Província Tocantins, Centro Oeste do Brasil Mineral chemistry and crystallization conditions of the Bom Jardim de Goiás pluton Tocantins Province
}

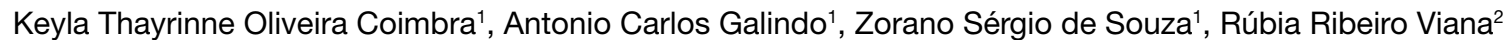 \\ ${ }^{1}$ Programa de Pós-Graduação em Geodinâmica e Geofísica da Universidade Federal do Rio Grande do Norte - UFRN, Avenida \\ Senador Salgado Filho, 3.000, Caixa Postal 1502, CEP 59078-970, Natal, RN, BR (keyla_thay@hotmail.com; \\ galindo@geologia.ufrn.br; zorano@geologia.ufrn.br) \\ ${ }^{2}$ Instituto de Ciência e Tecnologia, Universidade Federal dos Vales do Jequitinhonha e Mucuri - UFVJM, Diamantina, MG, BR \\ (rubia.viana@ict.ufvjm.br)
}

Recebido em 9 de agosto de 2015; aceito em 28 de abril de 2017

\begin{abstract}
Resumo
Intrusões graníticas pós-colisionais relacionadas ao Ciclo Brasiliano são de ampla distribuição no Arco Magmático de Goiás, porção central da Província Tocantins, Brasil Central. O Plutão Bom Jardim de Goiás (PBJG) compõe o quadro desses corpos intrusivos de idade ediacarana, cujo embasamento é constituído por rochas metassupracrustais e ortognaisses do Arco Magmático Arenópolis. De acordo com descrições petrográficas, as rochas do PBJG são classificadas em tonalito, granodiorito e quartzo monzodiorito, com textura equigranular grossa a inequigranular (fina a média); localmente observam-se fenocristais de anfibólio e plagioclásio. Neste trabalho são apresentados dados de química mineral de anfibólio, plagioclásio, biotita e magnetita do PBJG, assim como os parâmetros intensivos de cristalização do plutão em questão. O anfibólio do PBJG é subédrico ou anédrico, com características químicas apontando para os anfibólios cálcicos edenita e Mg-hornblenda. O plagioclásio (andesina, $\mathrm{An}_{30-37}$ ) ocorre como grãos prismáticos ou ripiformes, geminados, com zonamento químico evidenciado por alterações acentuadas para sericita, epídoto e carbonatos no centro dos cristais. A biotita é marrom, lamelar, sendo parcialmente substituída por titanita, clorita e epídoto, correspondendo quimicamente a Mg-biotita. A magnetita é euédrica a subédrica, em seções quadradas ou alongadas, encontrando-se usualmente como inclusões em hornblenda, clinopiroxênio, biotita e titanita. $\mathrm{O}$ teor de $\mathrm{Al}_{\mathrm{T}}$ da hornblenda indica pressão de cristalização do PBJG entre 2,1 e 4,0 kbar. Esses valores são coerentes com a presença de andalusita nas rochas encaixantes. O geotermômetro anfibólio-plagioclásio mostra temperaturas de 692 a $791^{\circ} \mathrm{C}$, relativamente mais baixas do que aquelas obtidas pelo geotermômetro de saturação de zircão em rocha total $\left(794-813^{\circ} \mathrm{C}\right)$, interpretadas como mais próximas da temperatura de liquidus de magmas granodioríticos a tonalíticos.
\end{abstract}

Palavras-chave: Província Tocantins; Ediacarano; Tonalitos; Geotermobarometria.

\begin{abstract}
Post-collisional granite intrusions related to the Brasiliano cycle are widespread in the Goiás Magmatic Arc, central part of the Tocantins Province, Central Brazil. The Bom Jardim de Goiás pluton (PBJG) is one of these intrusions of Ediacaran age, which are intrusive into metasupracrustal rocks and orthogneisses of the Arenópolis Magmatic arc. According to petrographic descriptions, the PBJG rocks are classified as tonalite, granodiorite and quartz monzodiorite, with coarse-grained equigranular to fine- to medium-grained inequigranular texture. This paper presents mineral chemistry of amphibole, plagioclase, biotite and magnetite from the PBJG and an estimation of intensive parameters of crystallization. The amphibole of the PBJG is subhedral or anhedral, with chemical characteristics of the calcic-amphiboles edenite and $\mathrm{Mg}$-hornblende. The plagioclase (andesine, $\left.\mathrm{An}_{30-37}\right) \operatorname{occurs}$ as prismatic or lath-like grains, twinned on the albite law, with chemical zoning evidenced by alteration to sericite, epidote and carbonates toward the centre of the crystals. Biotite is brown, lamellar, and partially replaced by titanite, chlorite and epidote; it corresponds chemically to Mg-biotite. The magnetite is euhedral or anhedral, with quadratic or elongated sections and usually observed as inclusions within hornblende, clinopyroxene, biotite and titanite. The $\mathrm{Al}_{\mathrm{T}}$ content of hornblende indicates crystallization pressure of 2.1 to $4.0 \mathrm{kbar}$ for the PBJG. These values are consistent with the presence of andalusite in the host rock. The amphibole-plagioclase geothermometer indicates temperatures between 692 and $791^{\circ} \mathrm{C}$, that are relatively lower than those obtained from whole rock zircon saturation geothermometer $\left(794-813^{\circ} \mathrm{C}\right)$, interpreted as closer to the liquidus temperature.
\end{abstract}

Keywords: Tocantins Province; Ediacaran; Tonalites; Geothermobarometry. 


\section{INTRODUÇÃO}

Os constituintes minerais de rochas ígneas são resultantes das condições físico-químicas às quais o magma é exposto durante o processo de resfriamento (Abbott e Clarke, 1979). Dessa forma, pesquisas relacionadas à análise química dos minerais são utilizadas para estimar os parâmetros intensivos de cristalizações, como pressão e temperatura de cristalização e fugacidade de oxigênio dos magmas graníticos; nesse contexto citam-se os autores Hammarstrom e Zen (1986), Lamarão e Dall'Agnol (2004), Hossain e Tsunogae (2014), Vilalva e Vlach (2014). Neste trabalho são apresentados resultados de análises químicas em anfibólio, plagioclásio, biotita e minerais opacos do Plutão Bom Jardim de Goiás (PBJG), além dos cálculos geotermobarométricos, objetivando a melhor compreensão das condições de colocação do plutão.

\section{GEOLOGIA REGIONAL}

A Província Tocantins, situada no Brasil Central, constitui uma das dez províncias estruturais brasileiras definidas por Almeida et al. (1981), tendo sido formada pela convergência entre os Crátons Amazônico e São Francisco-Congo e, possivelmente, o Bloco Paraná, contribuindo para a formação do supercontinente Gondwana ocidental. Essa Província é constituída pelas faixas de dobramento Paraguai e Araguaia (bordas sul e leste do Cráton Amazônico, respectivamente), Arco Magmático de Goiás e Faixa Brasília (borda oeste do Cráton São Francisco). O Arco Magmático de Goiás é um orógeno acrescionário formado entre 900 e $600 \mathrm{Ma}$, subdividido em Arco Magmático Arenópolis e Arco Magmático Mara Rosa, sul e norte, respectivamente. O Arco Magmático de Goiás compõe-se de ortognaisses tonalíticos e granodioríticos, associados a rochas metavulcânicas e metassedimentares, afetadas em graus variados por zonas de cisalhamento transcorrente e/ou de cavalgamento do final do neoproterozoico (Pimentel et al., 1999, 2000).

Tanto no Arco Magmático Arenópolis como no Arco Magmático Mara rosa ocorrem intrusões graníticas (biotita granito e leucogranito a duas micas) e gabro-dioríticas, pouco ou não deformadas, que constituem uma associação bimodal tardia a pós-orogênica, com idades que variam entre 630 e 590 Ma (Pimentel et al., 1996, 1999), além de corpos intrusivos de natureza máfica-ultramáfica (Pimentel et al., 2000). O Arco Magmático Arenópolis é formado por rochas de natureza cálcica a cálcio-alcalina, sendo divididas em:

- ortognaisses, portadores de hornblenda e biotita, apresentando feições como enclaves máficos deformados, diques leucocráticos tardios e texturas porfiríticas reliquiares que atestam a natureza plutônica dos protólitos, metamorfisados na fácies anfibolito;
- rochas supracrustais compreendendo metabasaltos, metandesitos, metadacitos, metarriolitos, mármores impuros, metachert, anfibolitos e metapelítos, metamorfisados nas fácies xisto verde e anfibolito (Pimentel et al., 1996, 2004).

Os protólitos ígneos das sequências ortognáissicas e metavulcânicas que compõem o Arco Magmático de Arenópolis cristalizaram em dois eventos distintos, descritos a seguir. Entre 950 e 800 Ma estão as rochas de natureza metaluminosa, representadas pelos ortognaisses Arenópolis, Matrinxã, Sancrelândia e Iporá, e as metavulcânicas de Arenópolis. Entre 764 e 587 Ma estão as rochas de natureza meta a peraluminosa, representadas pelos gnaisses Firminópolis, Turvânia e Palminópolis, e as metavulcânicas das sequências Jaupaci e Iporá (Pimentel et al., 2000, 2004; Laux et al., 2004). Intrusões pós-orogênicas compõem eventos de 590 a 560 e de 508 a $485 \mathrm{Ma}$, respectivamente granitos cálcio-alcalinos tipo I e granitos alcalinos tipo A (Pimentel et al., 2000).

Nesse cenário está o PBJG, objeto do presente estudo (Figura 1A), alojado nas unidades metaplutônicas e metassupracrustais do Arco Magmático de Arenópolis (Figura 1B). Análises U-Pb em zircão por ablação a laser mostram uma idade de cristalização de $550 \pm 12$ Ma para o plutão. Relações temporais com outros corpos neoproterozoicos intrusivos da região indicam que eles compõem o quadro de corpos pós-colisionais brasilianos do Arco Magmático de Arenópolis (Coimbra, 2015).

\section{METODOLOGIA}

Para classificação dos litotipos presentes na área, foram analisadas 15 lâminas delgadas, confeccionadas no Departamento de Geologia da Universidade Federal do Rio Grande do Norte (UFRN). As porcentagens modais foram obtidas por meio da contagem de 1.000 pontos por seção, com o auxílio de um microscópio petrográfico Leica DMLP do Programa de Pós-Graduação em Geodinâmica e Geofísica da UFRN, acoplado a um contador de pontos manual e monitorado via aplicativo Petroledge da Endeeper. A determinação do teor de anortita do plagioclásio tomou como base os dados de química mineral da amostra MK-8. Para as demais amostras, seguiu-se a metodologia da seção ortogonal a face (010) segundo o método Michel-Lévy clássico.

Considerando que o PBJG não apresenta variação textural e mineralógica significativa, as análises de química mineral foram realizadas em uma amostra representativa (MK-8), que foi analisada no Instituto de Geociências da Universidade de Brasília (UnB). Foi usada uma microssonda eletrônica modelo JEOL JXA-8230, equipada com quatro espectrômetros operando com aceleração de voltagem de $15 \mathrm{kV}$, corrente de 10-8 nA, tempo de contagem de $10 \mathrm{~s}$, utilizando minerais 
sintéticos e naturais como padrões. Os erros analíticos relativos são de ordem de $\pm 0,5-2 \%$ para $\mathrm{SiO}_{2}, \mathrm{Al}_{2} \mathrm{O}_{3}, \mathrm{Fe}_{2} \mathrm{O}_{3}$, $\mathrm{MgO}, \mathrm{MnO}, \mathrm{CaO}$ e $\mathrm{TiO}_{2}$, e 4,5-5,6\% para $\mathrm{Na}_{2} \mathrm{O}$ e $\mathrm{K}_{2} \mathrm{O}$.

Os resultados geoquímicos utilizados para discutir parâmetros intensivos de cristalização, por meio da saturação em $\mathrm{Zr}$ (ppm) em rocha total, foram obtidos a partir da análise química de 14 amostras representativas do PBJG (Coimbra, 2015) que foram preparadas no Laboratório Multiusuários de Técnicas Analíticas (LAMUTA) do Departamento de Recursos Minerais da Universidade Federal de Mato Grosso
(DRM/UFMT) utilizando o moinho de disco (marca AMEF) modelo AMP1-S com panela de carbeto de tungstênio. Depois de reduzidas a pó, as amostras foram enviadas para o Laboratório ALS Minerals (Goiânia, GO). Os procedimentos das análises seguiram a rotina disponibilizada no catálogo analítico online da ALS Minerals (2014). Os elementos maiores foram analisados pelo método Plasma de Indução Acoplado -Espectrometria de Emissão Atômica (ICP-AES), e os elementos traço e terras raras, por Plasma de Indução Acoplado - Espectroscopia de Massa (ICP-MS).

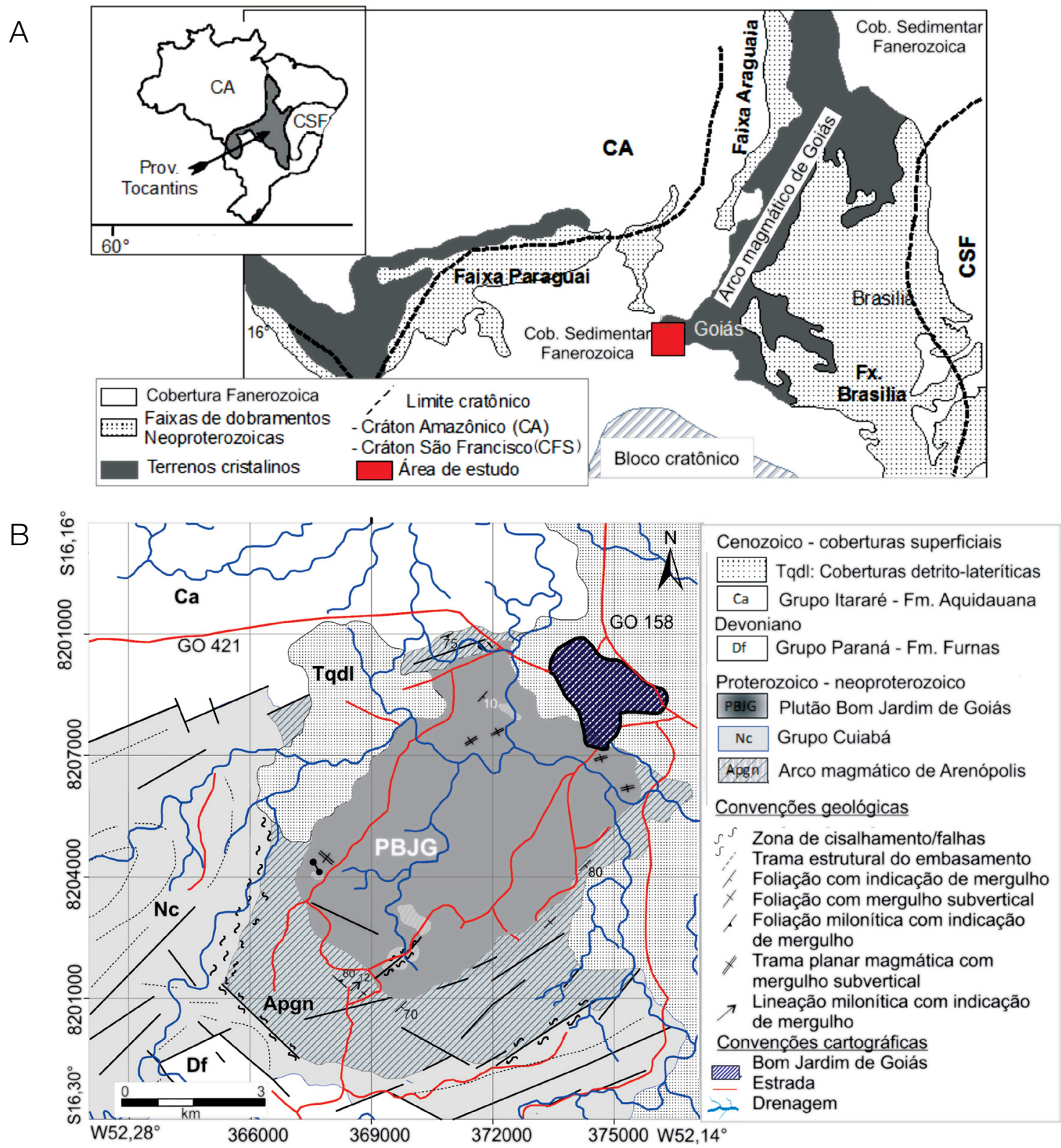

Figura 1. (A) Mapa esquemático localizando a área de estudo, mostrando os principais elementos do sistema orogenético Brasiliano/Pan-Africano (modificado de Viana et al., 1995). (B) Mapa geológico simplificado do Plutão Bom Jardim de Goiás (Coimbra, 2015). 


\section{GEOLOGIA DO PLUTÃO BOM JARDIM DE GOIÁS}

O PBJG é um corpo semicircular com cerca de $40 \mathrm{~km}^{2}$ de área. As relações de contato entre o plutão e as rochas do embasamento são intrusivas, evidenciadas por xenólitos centimétricos a métricos de rochas metavulcânicas no tonalito (Figura 2A). Além dos xenólitos, as rochas do embasamento ocorrem em forma de lajedos e blocos, que são observados principalmente em drenagens. Essas rochas estão associadas à sequência do Arco Magmático de Arenópolis.

As relações de contato entre os ortognaisses e a sequência metassupracrustal do Arco Magmático de Arenópolis são tectônicas indicam discordância intrusiva (Pimentel et al.,
1991). Os ortognaisses neoproterozoicos são representados por biotita gnaisses cinzas, frequentemente milonitizados, com texturas ígneas preservadas. As rochas metassupracrustais compreendem metadacitos, metariolitos e metassedimentos diversos. As rochas metavulcânicas ocorrem principalmente em faixas miloníticas; nesses locais são comuns estiramentos de quartzo e feldspatos, além de boudinage de bandas silicosas, e ainda sheets de biotita gnaisses extremamente estirados e concordantes com a foliação milonítica das metavulcânicas com mergulho forte $\left(80^{\circ}\right)$ para norte e perpendiculares à lineação milonítica de mergulho fraco $\left(12^{\circ}\right)$ para ENE.

As rochas metassedimentares são caracterizadas pela presença de aluminossilicatos (cordierita, fibrolita e andalusita), que indicam metamorfismo de baixa pressão na
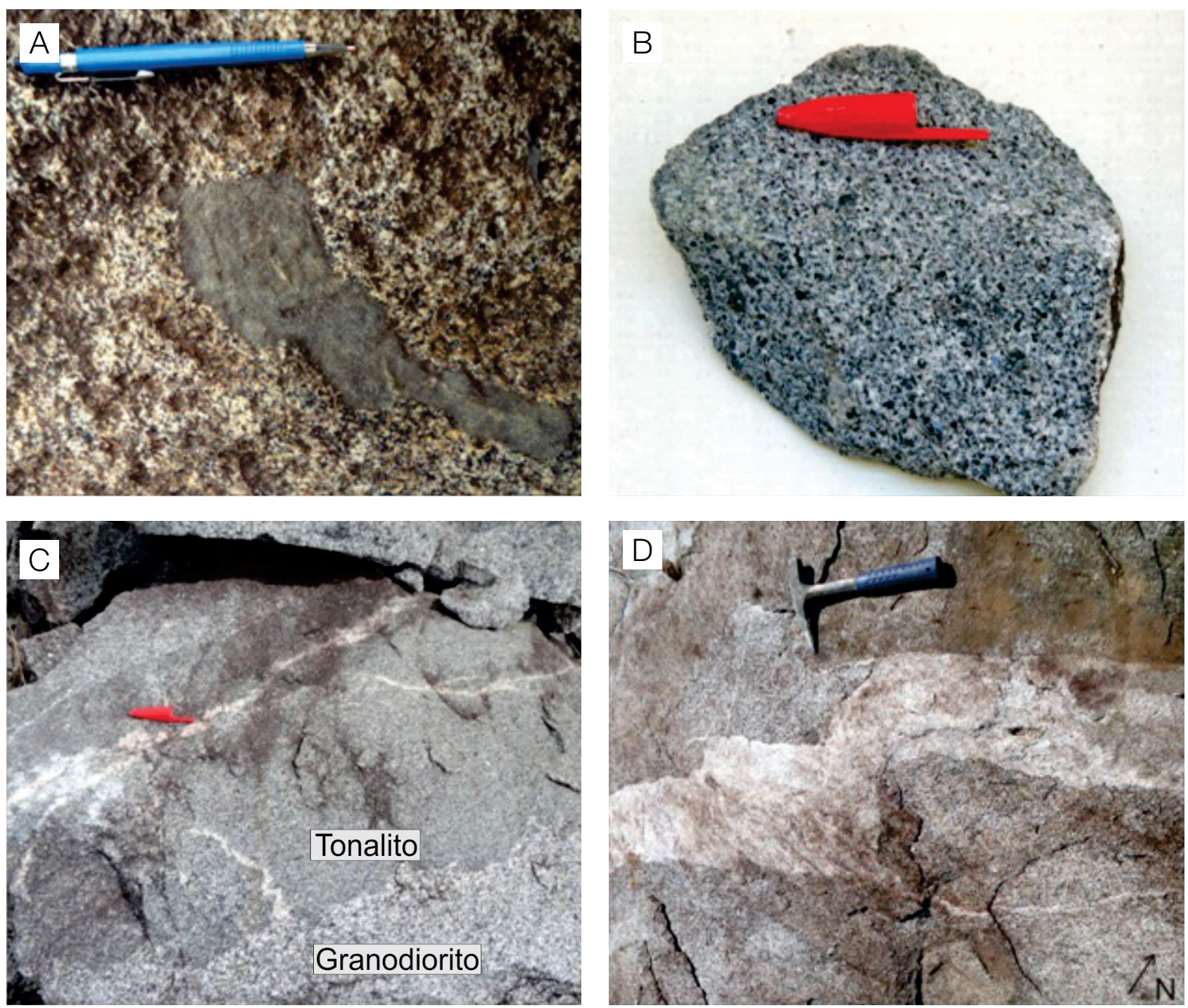

Figura 2. Feições mesoscópicas do plutão estudado e rochas encaixantes. (A) Tonalito com xenólito anguloso da unidade metavulcânica. (B) Aspecto macroscópico de tonalito. (C) Granodiorito em contato interdigitado com tonalito. (D) Dique de monzogranito intrusivo em tonalito. 
fácies anfibolito $\left(\mathrm{P}<4 \mathrm{kbar}, \mathrm{T}<600^{\circ} \mathrm{C}\right)$. As microtexturas observadas nas rochas dessa unidade são lepidogranoblásticas e granolepidoblásticas, inequigranulares finas a médias. Localmente, a xistosidade contínua é marcada pela recristalização de micas e quartzo, dispostos em cristais orientados, com tamanhos menores que $1 \mathrm{~mm}$, ou ainda por fibrolita. A mineralogia essencial é constituída por: quartzo, microclina e plagioclásio. Os acessórios são muscovita, cordierita, fibrolita, andalusita, turmalina, minerais opacos e apatita.

Os litotipos do plutão possuem tonalidade cinza (Figura 2B). Estruturalmente são isotrópicos, com textura equigranular média a grossa nas partes centrais, tendendo a tipos mais finos nas bordas do corpo. Tonalitos e granodioritos são predominantes e mostram contatos interdigitados sugestivos de coexistência de magmas (Figura 2C), com variação para quartzo monzodiorito. Por fim, citam-se diques tardios de leucogranito que interceptam as rochas do embasamento e demais litotipos do plutão (Figura 2D).

A afinidade geoquímica indica granito tipo-I, de natureza cálcio-alcalina, de potássio baixo a médio, para as rochas intermediárias do PBJG, que podem ser, em parte, comparadas com as intrusões pós-colisionais mais antigas. $\mathrm{O}$ caráter metaluminoso dessas rochas é creditado por pequena quantidade de $\mathrm{K} 2 \mathrm{O}$ e excesso de $\mathrm{CaO}$, refletindo a petrografia, que é rica em plagioclásio e anfibólio cálcico (Coimbra, 2015).

\section{Petrografia}

De acordo com o diagrama de classificação de Streckeisen (1976), as rochas intermediárias do PBJG são tonalitos, granodioritos e quartzo monzodioritos, além de monzogranito, que é o tipo mais evoluído, representativo do dique hololeucocrático (Tabela 1; Figura 3). A composição modal mostra que são rochas essencialmente leucocráticas a mesocráticas, tendendo a seguir a série de diferenciação cálcio-alcalina de potássio baixo ou médio. A textura das rochas do PBJG varia de equigranular grossa a inequigranular fina a média, localmente com fenocristais de anfibólio e plagioclásio. No tonalito, litotipo dominante, os critérios texturais indicam que magnetita, zircão e titanita são fases minerais precoces, seguidos de hornblenda, plagioclásio e biotita. A magnetita tem granulação média $(0,3 \mathrm{~mm})$, e hábito euédrico ou subédrico, mostrando contatos irregulares, ou incluídas em hornblenda (Figura 4A), clinopiroxênio, biotita e titanita. $\mathrm{O}$ zircão ocorre como grãos inclusos em biotita. A titanita é euédrica a subédrica, comumente em seções losangulares (Figura 4B).

A hornblenda possui pleocroísmo forte $\left(\mathrm{X}^{\prime}=\right.$ verde-claro, Y' = bege; moderado; Z' = verde azulado, moderado), com hábito subédrico ou anédrico em seções alongadas ou hexagonais que atingem de 1 a $4 \mathrm{~mm}$ (Figura 4C). Os cristais alongados possuem contatos regulares (com plagioclásio e quartzo) e irregulares (com biotita). Outras secções aparecem como inclusões em K-feldspato ou como cristais intergranulares com contatos irregulares com plagioclásio. Pode ocorrer substituição por clorita e epídoto tardio ou, ainda, inclusões de clinopiroxênio, titanita, apatita, minerais opacos e quartzo. O plagioclásio é do tipo andesina $\left(\mathrm{An}_{30-37}\right)$, os cristais são alongados prismáticos, ou ripiformes com geminação polissintética (Figura 4C),

Tabela 1. Composição modal das rochas do Plutão Bom Jardim de Goiás.

\begin{tabular}{|c|c|c|c|c|c|c|c|c|c|c|c|c|c|c|c|}
\hline LITOLOGIA & $\begin{array}{c}\text { Quartzo } \\
\text { monzodiorito }\end{array}$ & & & & & Tonalito & & & & & & Granoc & diorito & & $\begin{array}{c}\text { Dique de } \\
\text { granodiorito/ } \\
\text { monzogranito }\end{array}$ \\
\hline AMOSTRA & MK1B & MK8 & MK15A & MK16C & MK18 & MK19A & Mk19B & MK20 & MK21 & MK31 & MK12 & MK13 & MK3А & MK1A & MK15B \\
\hline Quartzo & 12,4 & 13,5 & 17,5 & 22,4 & 22,5 & 8,3 & 22,0 & 24,9 & 24,6 & 18,8 & 17,7 & 18,3 & 18,1 & 18,2 & 34,1 \\
\hline Microclina & 6,6 & 2,5 & 3,7 & 3,7 & 3,7 & 0,2 & 0,8 & 1,7 & 0,5 & 0,6 & 6,0 & 11,9 & 11,0 & 14,9 & 21,5 \\
\hline Plagioclásio & 50,3 & 46,3 & 52,1 & 41,4 & 41,4 & 31,4 & 43,0 & 47,5 & 41,6 & 42,0 & 46,9 & 39,4 & 46,1 & 28,1 & 38,9 \\
\hline Biotita & 8,5 & 9,3 & 11,0 & 7,6 & 7,6 & 5,2 & 5,0 & 16,0 & 4,0 & 15,3 & 9,4 & 2,6 & 5,2 & 15,6 & 3,4 \\
\hline Hornblenda & 14,3 & 24,2 & 13,0 & 22,3 & 22,3 & 47,5 & 9,0 & 6,5 & 8,7 & 18,6 & 18,5 & 22,8 & 17,0 & 14,7 & - \\
\hline Clinopiroxênio & 1,0 & - & 0,3 & - & - & 3,0 & 10,0 & 1,1 & 8,5 & 2,3 & - & 1,0 & 0,3 & 2,2 & - \\
\hline Titanita & 1,2 & 0,1 & 0,5 & 0,8 & 0,8 & - & 1,0 & 0,2 & - & 0,3 & 0,2 & 0,1 & 0,2 & 0,6 & 0,2 \\
\hline Zircão & - & - & - & - & - & 0,1 & - & - & - & 0,1 & - & - & - & 0,1 & - \\
\hline Opacos & 1,3 & 0,2 & 0,3 & 1,1 & 1,1 & 0,4 & 6,5 & 0,2 & 6,6 & 0,5 & 0,4 & 0,8 & 1,2 & 0,3 & 0,2 \\
\hline Apatita & 0,1 & - & - & - & - & 0,1 & - & - & - & 0,2 & - & - & - & 0,3 & - \\
\hline $\begin{array}{l}\text { Minerais } \\
\text { secundários }\end{array}$ & 4,3 & 3,9 & 1,6 & 0,6 & 0,6 & 3,8 & 2,7 & 1,9 & 5,5 & 1,3 & 0,9 & 3,1 & 0,9 & 5,0 & 1,7 \\
\hline Total & 100 & 100 & 100 & 100 & 100 & 100 & 100 & 100 & 100 & 100 & 100 & 100 & 100 & 100 & 100 \\
\hline $\bar{Q}$ & 17,9 & 21,7 & 36,1 & 39,4 & 33,3 & 20,8 & 33,4 & 33,6 & 36,9 & 30,6 & 25,1 & 26,2 & 24,1 & 29,7 & 36,1 \\
\hline A & 9,5 & 4,0 & 22,8 & 1,3 & 5,5 & 0,5 & 1,2 & 2,3 & 0,7 & 1,0 & 8,5 & 17,1 & 14,6 & 24,4 & 22,8 \\
\hline $\mathrm{P}$ & 72,6 & 74,3 & 41,2 & 59,3 & 61,2 & 78,7 & 65,3 & 64,1 & 62,4 & 68,4 & 66,4 & 56,6 & 61,3 & 45,9 & 41,2 \\
\hline Máficos & 26,3 & 33,8 & 25,1 & 31,8 & 31,8 & 56,2 & 31,5 & 24,0 & 27,8 & 37,1 & 28,5 & 27,3 & 23,9 & 33,5 & 3,8 \\
\hline$A+P$ & 56,9 & 48,8 & 55,8 & 45,1 & 45,1 & 31,6 & 43,8 & 49,2 & 42,1 & 42,6 & 52,9 & 51,3 & 57,1 & 43,0 & 60,4 \\
\hline
\end{tabular}

*Minerais secundários: Carbonatos, epídoto, e mica branca. 
com tamanho de 2 a $6 \mathrm{~mm}$. É comum o zonamento químico, demonstrado por alteração mais acentuada nas partes centrais (Figura 4D).

A biotita exibe pleocroísmo forte $\left(\mathrm{X}^{\prime}=\right.$ castanho amarronzado, $Y^{\prime}=$ bege claro, $Z^{\prime}$ = bege escuro), hábito lamelar, tamanho de $\sim 0,2-0,3 \mathrm{~mm}$; está preservada ou parcialmente substituída por clorita, titanita e epídoto secundário. O clinopiroxênio é verde pálido, atinge até $3 \mathrm{~mm}$, sendo observado como relictos no núcleo de anfibólio. O quartzo granular $(<0,2 \mathrm{~mm})$ está incluso em hornblenda, plagioclásio e microclina, ao passo que os cristais de quartzo anédricos são intersticiais $(0,2$ a $0,3 \mathrm{~mm})$. A microclina $(\sim 1 \mathrm{a} 2 \mathrm{~mm})$ exibe macla na lei da albita-periclínio e lamelas de exsolução pertítica tipo flaser.

O granodiorito e o quartzo monzodiorito possuem associações minerais e relações texturais muitos similares àquelas observadas no tonalito, porém apresentam maior porcentagem de K-feldspato modal. Já o dique de leucogranito possui textura equigranular média e fases acessórias compreendendo apatita, biotita, minerais opacos e zircão, inclusos em plagioclásio e microclina. Cristais prismáticos de plagioclásio são geminados na lei da albita com tamanho de 2 a $3 \mathrm{~mm}$; o núcleo desses minerais é parcialmente substituído por carbonatos e mica branca. O quartzo anédrico, intersticial $(\sim 0,3 \mathrm{~mm})$ mostra extinção ondulante. Por fim, a microclina anédrica $(\sim 0,3 \mathrm{~mm})$ exibe geminação típica em padrão xadrez $\mathrm{e}$ exsolução pertítica.

\section{QUÍMICA MINERAL}

\section{Anfibólio}

Foram realizadas sete análises de anfibólio (tonalito MK8) do PBJG, sendo três análises de centro e quatro de borda. Os dados obtidos estão na Tabela 2. A classificação química teve como base a fórmula estrutural geral, calculada assumindo 23 oxigênios (Leake et al., 1997), sendo representada por:

$$
\begin{aligned}
& \left(\mathrm{Na}_{0,18-0,31} \mathrm{~K}_{0,18-0,22}\right)\left(\mathrm{Ca}_{1,75-1,92} \mathrm{Na}_{0,08-0,22} \mathrm{Fe}^{2+}{ }_{0-0,03}\right) \\
& \left(\mathrm{Mg}_{2,64-2,87} \mathrm{Fe}^{2+}{ }_{1,33-1,1,63} \mathrm{Fe}^{3+}{ }_{0,28-0,54} \mathrm{Mn}_{0,02-04} \mathrm{Ti}_{0,13-0,26}\right. \\
& \left.\mathrm{Al}_{0,18-0,07}\right)\left(\mathrm{Si}_{6,64-6,78} \mathrm{Al}_{1,22-1,38}\right) \mathrm{O}_{22}\left(\mathrm{OH}_{2}\right)
\end{aligned}
$$

Os anfibólios do PBJG possuem composições bastante homogêneas, com razões $\mathrm{Mg} /(\mathrm{Mg}+\mathrm{Fe})$ entre $0,58-0,62$ e óxidos $\mathrm{TiO}_{2}=1,18-2,35 \%$ em peso, $\mathrm{Al}_{2} \mathrm{O}_{3}=7,76-9,65 \%$ em peso, $\mathrm{FeO}=14,39-15,18 \%$ em peso, $\mathrm{MgO}=11,18$ $-13,07 \%$ em peso, $\mathrm{MnO}=0,18-0,31 \%$ em peso, $\mathrm{CaO}=$ $10,98-11,77 \%$ em peso, $\mathrm{Na}_{2} \mathrm{O}=1,10-1,70 \%$ em peso e $\mathrm{K}_{2} \mathrm{O}=1,03-1,17 \%$ em peso. As características químicas apontam para anfibólio cálcico com valores de $\mathrm{Ca}_{M 4}$ superiores a $1,75 \mathrm{pfu}$ (por fórmula unitária), sendo classificados como edenita e Mg-hornblenda, conforme Figuras 5A e B (Leake et al., 1997).

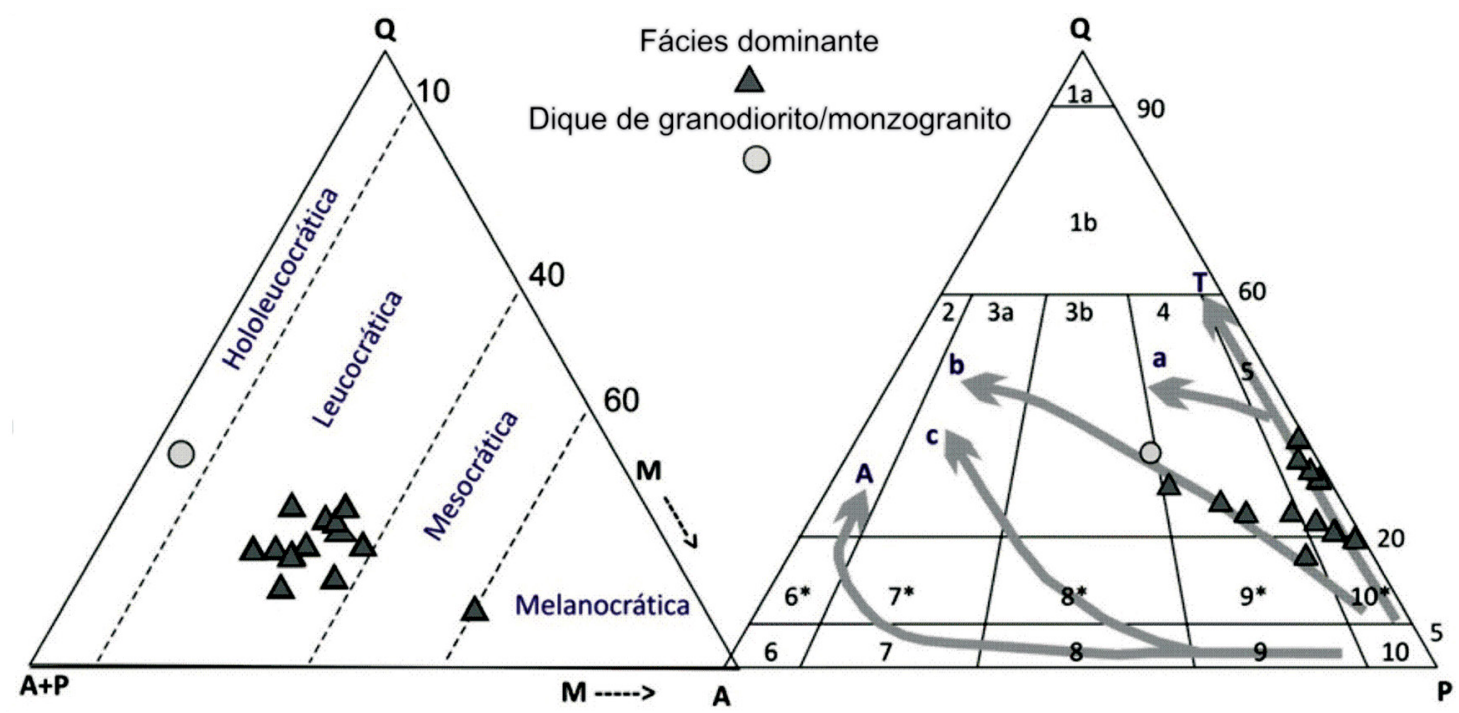

Figura 3. Classificação das rochas do Plutão Bom Jardim de Goiás nos diagramas Q-(A + P)M e QAP de Streckeisen (1976): $Q=$ quartzo, $A=$ feldspato alcalino, $P=$ plagioclásio $(A n>5 \%), M=$ total de minerais máficos. Séries magmáticas segundo Lameyre e Bowden (1982): toleítica (T), alcalina (A), cálcio alcalina de baixo, intermediário e alto potássio (a, b e c, respectivamente). Quartzolito (1a); granitoide rico em quartzo (1b); álcali-feldspato granito (2); sienogranito (3a); monzogranito (3b); granodiorito (4); tonalito (5); álcali-feldspato sienito (6); álcali-feldspato quartzo sienito (6*); sienito (7); quartzo sienito $\left(6^{\star}\right)$; monzonito (8); quarzo monzonito (8*); monzodiorito/monzogabro (9); quartzo monzodiorito/quartzo monzogabro (9*); diorito/gabro (10); quartzo diorito/quartzo gabro (10*). 


\section{Biotita}

Foram realizadas cinco análises de biotita do PBJG, três obtidas no centro de cristais distintos e duas em um mesmo cristal (borda e centro). As fórmulas estruturais foram calculadas para 22 oxigênios, assumindo todo o ferro presente como $\mathrm{Fe}^{2+}$ (Tabela 3). A fórmula geral determinada para a biotita é:

$\left(\mathrm{K}_{1,77-1,84} \mathrm{Na}_{0,01-0,03}\right)\left(\mathrm{Mg}_{2,98-3,07} \mathrm{Fe}^{2+}{ }_{2,05-2,13} \mathrm{Mn}_{0,01-0,03}\right.$

$\left.\mathrm{Al}_{0,12-0,19}\right)\left(\mathrm{Al}_{2,31-2,35} \mathrm{Si}_{5,65-5,69}\right) \mathrm{O}_{20}(\mathrm{OH}, \mathrm{F}, \mathrm{Cl})_{4}$
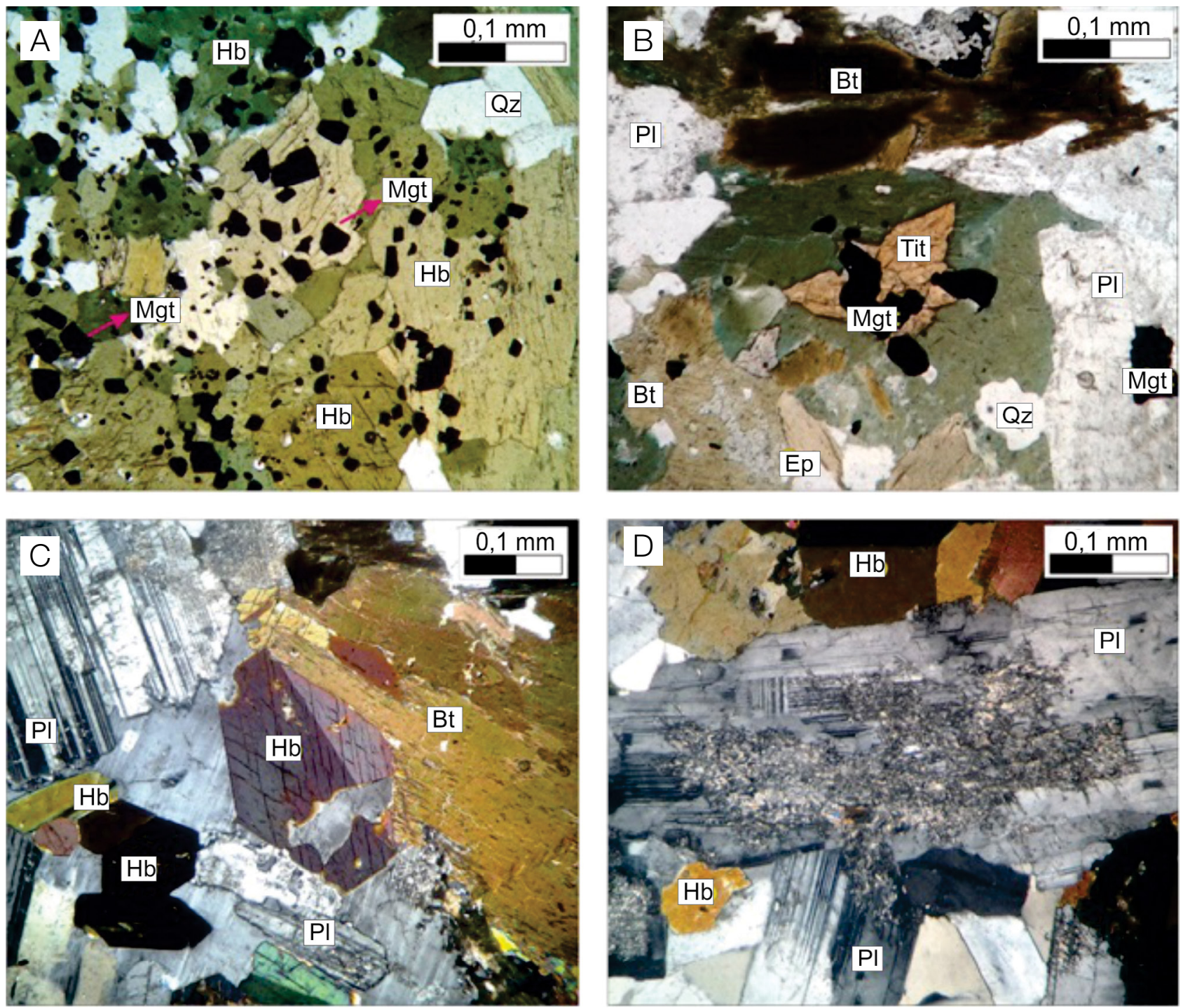

Hb: hornblenda; Bt: biotita; PI: plagioclásio; Qz: quartzo; Mgt: magnetita, Tit: titanita

Figura 4. Fotomicrografias apresentando as relações texturais no tonalito. (A) Concentração de cristais de magnetita, inclusos em hornblenda. (B) Associação titanita + opacos + hornblenda + quartzo. (C) Hornblenda hexagonal maclada e plagioclásio com geminação polissintética. (D) Detalhe de fenocristal de plagioclásio mostrando partes centrais alteradas para mica branca + calcita. 
é a diminuição considerável dos conteúdos de $\mathrm{TiO}_{2}$ e $\mathrm{MgO}$ dessas biotitas, sendo o primeiro, provavelmente, utilizado na formação de titanita, e o segundo, na formação de clorita. Essas transformações são observadas petrograficamente. Quando projetadas no diagrama proposto por Abdel-Rahman (1994), usado como indicador de associações magmáticas, as amostras do PBJG indicam biotitas de magmas cálcio alcalinos (Figura 6D).

\section{Plagioclásio}

Para o plagioclásio do PBJG, cinco análises químicas foram realizadas, sendo duas no centro de diferentes cristais e três

Tabela 2. Análises de anfibólios (calculados para 23 oxigênios) do Plutão Bom Jardim de Goiás (tonalito MK8) obtidas por microssonda eletrônica.

\begin{tabular}{|c|c|c|c|c|c|c|c|}
\hline Cristal & 1 & 2 & 4 & 5 & & 6 & \\
\hline $\begin{array}{l}\mathrm{N}^{\circ} \text { da } \\
\text { análise }\end{array}$ & 5 & 6 & 9 & 13 & 16 & 17 & 18 \\
\hline Posição & $b$ & c & c & b & $\mathrm{c}$ & b & b \\
\hline $\mathrm{SiO}_{2}$ & 45,63 & 44,67 & 44,45 & 45,68 & 43,79 & 45,55 & 44,67 \\
\hline $\mathrm{TiO}_{2}$ & 1,53 & 1,88 & 1,94 & 1,18 & 2,30 & 1,25 & 2,35 \\
\hline $\mathrm{Al}_{2} \mathrm{O}_{3}$ & 8,43 & 8,91 & 8,58 & 8,49 & 9,65 & 8,54 & 9,31 \\
\hline $\mathrm{FeO}$ & 14,79 & 14,95 & 14,59 & 15,18 & 14,82 & 14,46 & 14,82 \\
\hline $\mathrm{MgO}$ & 12,80 & 12,34 & 12,32 & 12,33 & 11,69 & 13,07 & 11,98 \\
\hline $\mathrm{MnO}$ & 0,22 & 0,22 & 0,18 & 0,31 & 0,26 & 0,31 & 0,25 \\
\hline $\mathrm{CaO}$ & 11,30 & 10,98 & 11,77 & 11,08 & 11,35 & 11,36 & 11,17 \\
\hline $\mathrm{Na}_{2} \mathrm{O}$ & 1,50 & 1,78 & 1,43 & 1,29 & 1,70 & 1,41 & 1,44 \\
\hline $\mathrm{K}_{2} \mathrm{O}$ & 1,03 & 1,14 & 1,08 & 1,03 & 1,17 & 0,96 & 1,12 \\
\hline Total & 97,23 & 96,87 & 96,34 & 96,57 & 96,73 & 96,91 & 97,11 \\
\hline $\mathrm{Si}$ & 6,73 & 6,64 & 6,66 & 6,78 & 6,55 & 6,72 & 6,62 \\
\hline $\mathrm{Al}^{\text {iv }}$ & 1,27 & 1,36 & 1,34 & 1,22 & 1 & 1,28 & ,38 \\
\hline Soma T & 8,00 & 8,00 & 8,00 & 8,00 & 8,00 & 8,00 & 8,00 \\
\hline $\mathrm{Ti}$ & 0,17 & 0,21 & 0,22 & 0,13 & 0,26 & 0,14 & 0,26 \\
\hline Al vi & 0,20 & 0,20 & 0,18 & 0,27 & 0,25 & 0,21 & 0,24 \\
\hline $\mathrm{Fe}^{2+}$ & 1,32 & 1,37 & 1,49 & 1,33 & 1,51 & 1,21 & 1,41 \\
\hline $\mathrm{Fe}^{3+}$ & 0,47 & 0,45 & 0,34 & 0,51 & 0,34 & 0,54 & 0,41 \\
\hline $\mathrm{Mn}$ & 0,03 & 0,03 & 0,02 & 0,04 & 0,03 & 0,04 & 0,03 \\
\hline $\mathrm{Mg}$ & 2,81 & 2,73 & 2,76 & 2,73 & 2,61 & 2,87 & 2,65 \\
\hline $\mathrm{Ca}$ & 0,00 & 0,00 & 0,00 & 0,00 & 0,00 & 0,00 & 0,00 \\
\hline $\begin{array}{l}\text { Soma } \\
M 1,2,3\end{array}$ & 5,00 & 5,00 & 5,00 & 5,00 & 5,00 & 5,00 & 5,00 \\
\hline$\overline{\mathrm{Fe}^{2+}}$ & 0,03 & 0,03 & 0,00 & 0,05 & 0,00 & 0,04 & 0,02 \\
\hline $\mathrm{Ca}$ & 1,79 & 1,75 & 1,89 & 1,76 & 1,81 & 1,80 & 1,77 \\
\hline $\mathrm{Na}$ & 0,18 & 0,22 & 0,12 & 0,19 & 0,19 & 0,16 & 0,21 \\
\hline Soma M4 & 2,00 & 2,00 & 2,00 & 2,00 & 2,00 & 2,00 & 2,00 \\
\hline $\mathrm{Na}$ & 0,25 & 0,29 & 0,30 & 0,18 & 0,31 & 0,24 & 0,20 \\
\hline K & 0,19 & 0,22 & 0,21 & 0,20 & 0,22 & 0,18 & 0,21 \\
\hline Soma A & 0,44 & 0,51 & 0,51 & 0,38 & 0,53 & 0,42 & 0,41 \\
\hline $\begin{array}{l}\text { Soma- } \\
\text { cátions }\end{array}$ & 15,44 & 15,51 & 15,51 & 15,37 & 15,53 & 15,42 & 15,42 \\
\hline $\begin{array}{l}\mathrm{Mg} / \\
(\mathrm{Mg}+\mathrm{Fe})\end{array}$ & 0,61 & 0,60 & 0,60 & 0,59 & 0,59 & 0,62 & 0,59 \\
\hline
\end{tabular}

constituindo um perfil transversal em um mesmo cristal (centro/borda). As fórmulas estruturais foram calculadas para 32 oxigênios (Deer et al., 1992).

As composições são relativamente homogêneas, correspondendo a andesina. A variação de composição, no geral, tem um comportamento normal, apresentando núcleo com teores um pouco mais elevados de anortita $\left(\mathrm{An}_{34-37 \%}\right) \mathrm{em}$ comparação às bordas $\left(\mathrm{An}_{30-31 \%}\right)$ (Tabela 4). Na Figura 7, as amostras foram plotadas no diagrama ternário Or-Ab-An, com as isotermas calculadas com base no modelo de Furhman e Lindsley (1988), para 4,3 kbar, usando o software SOLVCALC (Wen e Nekvasil, 1994). O diagrama mostra temperatura aproximada de solidus entre 600 e $700^{\circ} \mathrm{C}$.
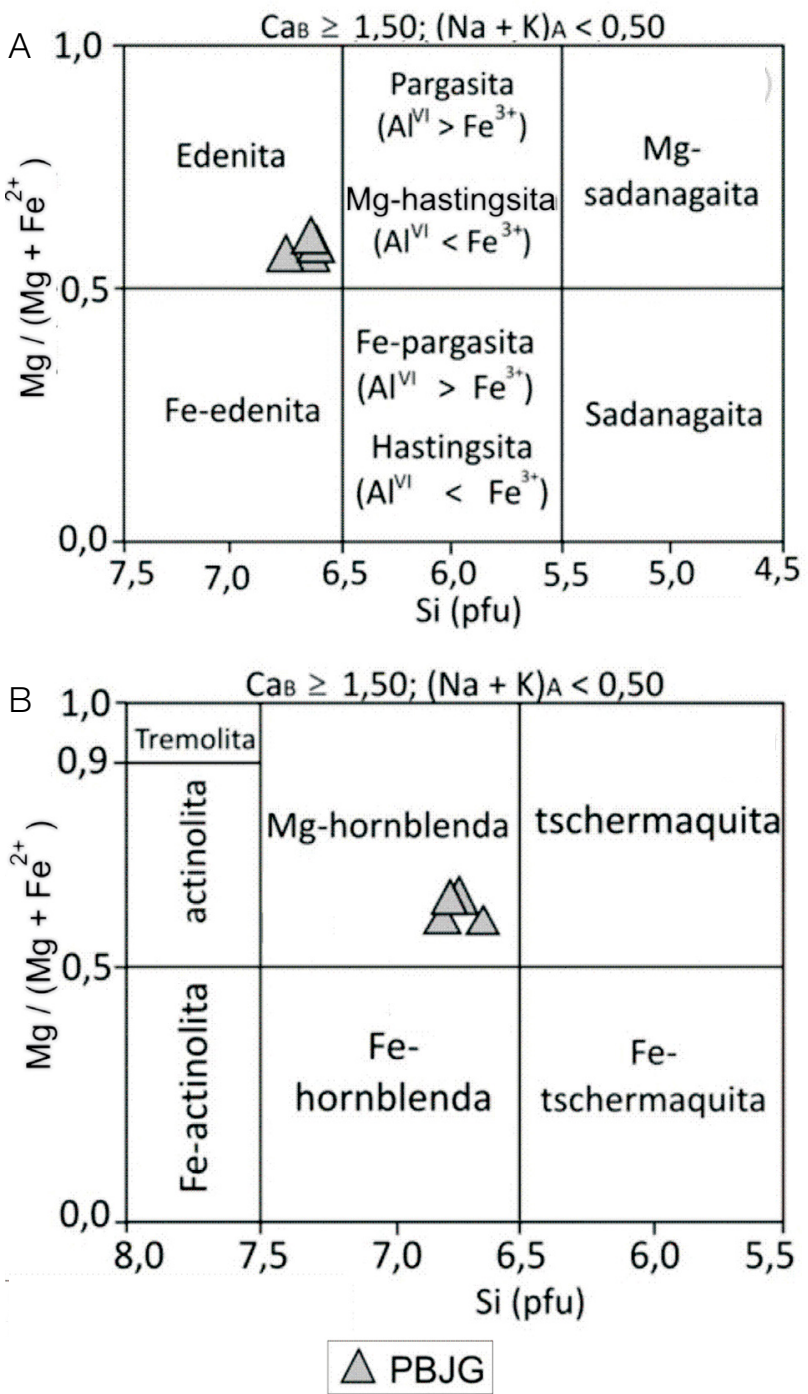

PBJG: Plutão Bom Jardim de Goiás.

Figura 5. Diagrama de classificação de anfibólios cálcicos (Leake et al., 1997). Análise representativa das rochas intermediárias do Plutão Bom Jardim de Goiás. 


\section{Minerais opacos}

Foram obtidas análises químicas pontuais no núcleo de quatro cristais distintos (Tabela 5). Os grãos analisados não apresentam conteúdos consideráveis de $\mathrm{Ti}\left(\mathrm{TiO}_{2}<0,04 \%\right.$ em peso), $\mathrm{Al}\left(\mathrm{Al}_{2} \mathrm{O}_{3}<0,10 \%\right.$ em peso $)$ e $\mathrm{Mn}(\mathrm{MnO}<0,15 \%$ em peso $)$, tratando-se, portanto, de magnetita pura, com $\mathrm{Fe}^{3+} \sim 15,98$ pfu $\mathrm{e} \mathrm{Fe}^{2+} \sim 7,99 \mathrm{pfu}$. Desse modo, os opacos descritos fazem parte do grupo dos espinélios, cuja fórmula geral é $\mathrm{R}_{8}^{2+} \mathrm{R}_{16}^{3+} \mathrm{O}_{32}$, sendo magnetita do grupo de espinélios invertidos, escrita como:

$\mathrm{Fe}^{3+}\left(\mathrm{Fe}^{2+} \mathrm{Fe}^{3+}\right) \mathrm{O}_{4}$

$\mathrm{Na}$ estrutura cristalina, pequenas quantidades de $\mathrm{Al}$ podem substituir o $\mathrm{Fe}^{3+}$ em geral, de modo semelhante, pequenas proporções de $\mathrm{Ca}, \mathrm{Mn}$ e $\mathrm{Mg}$ substituem o $\mathrm{Fe}^{2+}$,

Tabela 3. Análises de biotitas (calculadas para 22 oxigênios) do Plutão Bom Jardim de Goiás (tonalito MK8) obtidas por microssonda eletrônica.

\begin{tabular}{|c|c|c|c|c|c|}
\hline \multirow{2}{*}{$\begin{array}{l}\text { Cristal } \\
N^{\circ} \text { da análise }\end{array}$} & \multicolumn{2}{|c|}{1} & \multirow{2}{*}{$\begin{array}{c}2 \\
P-3\end{array}$} & \multirow{2}{*}{$\begin{array}{c}3 \\
P-4\end{array}$} & \multirow{2}{*}{$\begin{array}{c}4 \\
P-14\end{array}$} \\
\hline & $P-1$ & P-2 & & & \\
\hline Posição & c & B & C & C & c \\
\hline $\mathrm{SiO}_{2}$ (\%peso) & 36,86 & 37,05 & 37,28 & 37,27 & 37,11 \\
\hline $\mathrm{TiO}_{2}$ & 3,46 & 3,74 & 3,87 & 3,6 & 3,7 \\
\hline $\mathrm{Al}_{2} \mathrm{O}_{3}$ & 13,9 & 13,86 & 14 & 14,03 & 13,72 \\
\hline $\mathrm{FeO}$ & 16,28 & 16,34 & 16,21 & 16,11 & 16,73 \\
\hline $\mathrm{MnO}$ & 0,23 & 0,1 & 0,18 & 0,08 & 0,2 \\
\hline $\mathrm{MgO}$ & 13,41 & 13,04 & 13,52 & 13,55 & 13,48 \\
\hline $\mathrm{CaO}$ & 0,02 & 0,01 & 0,01 & 0,06 & 0,01 \\
\hline $\mathrm{Na}_{2} \mathrm{O}$ & 0,1 & 0,08 & 0,05 & 0,03 & 0,11 \\
\hline $\mathrm{K}_{2} \mathrm{O}$ & 9,43 & 9,05 & 9,44 & 9,3 & 9,38 \\
\hline Total & 93,69 & 93,01 & 94,56 & 94,03 & 94,55 \\
\hline Si (pfu) & 5,65 & 5,69 & 5,65 & 5,67 & 5,65 \\
\hline $\mathrm{Al}^{\mathrm{IV}}$ & 2,35 & 2,31 & 2,35 & 2,33 & 2,35 \\
\hline Soma - Z & 8 & 8 & 8 & 8 & 8 \\
\hline $\mathrm{Ti}$ & 0,4 & 0,43 & 0,44 & 0,41 & 0,42 \\
\hline $\mathrm{Al}^{\mathrm{VI}}$ & 0,17 & 0,2 & 0,16 & 0,19 & 0,12 \\
\hline $\mathrm{Fe}^{+2}$ & 2,09 & 2,1 & 2,06 & 2,05 & 2,13 \\
\hline $\mathrm{Mn}$ & 0,03 & 0,01 & 0,02 & 0,01 & 0,03 \\
\hline $\mathrm{Mg}$ & 3,07 & 2,98 & 3,06 & 3,07 & 3,06 \\
\hline Soma - Y & 5,76 & 5,72 & 5,74 & 5,73 & 5,76 \\
\hline $\mathrm{Ca}$ & - & - & - & 0,01 & - \\
\hline $\mathrm{Na}$ & 0,03 & 0,02 & 0,01 & 0,01 & 0,03 \\
\hline K & 1,84 & 1,77 & 1,83 & 1,81 & 1,82 \\
\hline Soma - X & 1,87 & 1,79 & 1,84 & 1,83 & 1,85 \\
\hline Soma-cátions & 15,63 & 15,52 & 15,57 & 15,56 & 15,62 \\
\hline $\mathrm{Fe}^{2+} /\left(\mathrm{Fe}^{2+}+\mathrm{Mg}\right)$ & 0,41 & 0,41 & 0,40 & 0,40 & 0,41 \\
\hline
\end{tabular}

${ }^{*} \mathrm{C}$ : centro. b: borda. embora possa ocorrer uma troca contínua entre $\mathrm{Mg}$ e $\mathrm{Fe}^{2+}$ (Deer et al., 1992). A fórmula estrutural foi calculada usando quatro oxigênios, assumindo a razão $\mathrm{Fe}_{2} \mathrm{O}_{3} / \mathrm{FeO}$ de acordo com Carmichael (1967).

\section{CONDIÇÕES DE CRISTALIZAÇÃO DO PLUTÃO BOM JARDIM DE GOIÁS}

\section{Pressão e temperatura}

A associação mineral hornblenda + biotita \pm titanita + magnetita (+ quartzo + plagioclásio \pm feldspato alcalino) encontrada na fácies tonalítica do PBJG possibilitou a aplicação do geobarômetro Al em anfibólio. Para estimativa de pressão, foram realizados cálculos com base no teor de $\mathrm{Al}$ em anfibólio de acordo com as Equações 1) Schmidt (1992); e (3) Anderson e Smith (1995).

As estimativas de pressão obtidas com os geobarômetros foram empregadas na Equação 3, que utiliza a composição do par anfibólio-plagioclásio para determinar a temperatura do sistema próximo ao solidus (Holland e Blundy, 1994). $\mathrm{O}$ geotermômetro foi calculado considerando os teores de anortita do centro $\left(\mathrm{An}_{37 \%}\right)$ e da borda $\left(\mathrm{An}_{30 \%}\right)$, demonstrados na Tabela 6 .

$\left.\mathrm{P}( \pm 0,6)=-3,01+4,76 \mathrm{~A} 1_{\mathrm{T}-\mathrm{Hbl}}\right)$

(Schmidt, 1992)

$T \pm 313 K=\frac{81,44-33,6 \mathrm{X}_{\mathrm{Na}}^{\mathrm{M} 4}-(66,88-2,92 \mathrm{P}[\mathrm{kbar}]) \mathrm{X}_{\mathrm{Al}}^{\mathrm{M} 2}+78,5 \mathrm{X}_{\mathrm{Al}}^{\mathrm{T} 1}+9,4 \mathrm{X}_{\mathrm{Na}}^{\mathrm{A}}}{0,0721-0,0083144 \ln \left(\frac{27 \mathrm{X}_{\mathrm{Na}}^{\mathrm{Ma}} X_{\mathrm{Si}}^{\mathrm{Tl}} X_{\mathrm{Al}}^{\mathrm{T} 1} X_{\mathrm{Ap}}^{\mathrm{Pla}}}{64 \mathrm{X}_{\mathrm{Ca}}^{\mathrm{M}} \mathrm{X}^{\mathrm{Tl}} \mathrm{X}_{\mathrm{Al}}^{\mathrm{Tl}} \mathrm{X}_{\mathrm{Ab}}^{\mathrm{Plag}}}\right)}$

(Holland e Blundy, 1994)

Na equação acima, $\mathrm{X}_{A b}$ é a fração molar de albita no plagioclásio e $\mathrm{X}^{T 1, M 4, M 2 \ldots}$ representa os sítios catiônicos dos respectivos elementos, sendo $\mathrm{T}$ dada graus Celsius e $\mathrm{P}$ em kbar.

$\mathrm{P}( \pm 0,6)=4,76 \mathrm{Al}-3,01-\left(\frac{\mathrm{T}^{\circ}-675}{85}\right) 0,530 \mathrm{Al}+0,005294(\mathrm{~T}-675)$

(Anderson e Smith, 1995)

Os resultados das interações entre os geobarômetros e os geotermômetros podem ser observados na Tabela 6 . Nota-se que para a Equação 1 a $P$ varia entre 3,97 e 5,08 kbar. Quando utilizados esses valores na Equação 2, as temperaturas obtidas foram na faixa de 692 a $777^{\circ} \mathrm{C}$. Já o geobarômetro da Equação 3, de Anderson e Smith (1995), mostrou resultados entre 2,1 e 4,0 kbar. Esses valores foram empregados também na Equação 2, resultando em temperaturas entre 693 e $799^{\circ} \mathrm{C}$. 
O zircão é uma das fases cristalizadas precocemente do magma, permitindo, assim, usar a concentração de zircônio na rocha como geotermômetro. Essa hipótese assume que o magma estava saturado nesse elemento. Para o cálculo de temperaturas, foram usadas as Equações 4 e 5, de Watson e Harrison (1983) e Boehnke et al. (2013), respectivamente, mostradas a seguir:

$\mathrm{T}\left({ }^{\circ} \mathrm{K}\right)=12900 /\left[\ln \left(\mathrm{D}^{Z r / m a g m a} / \mathrm{Zr}_{R T}\right)+3,8+0,85(\mathrm{M}-1)\right]$

A

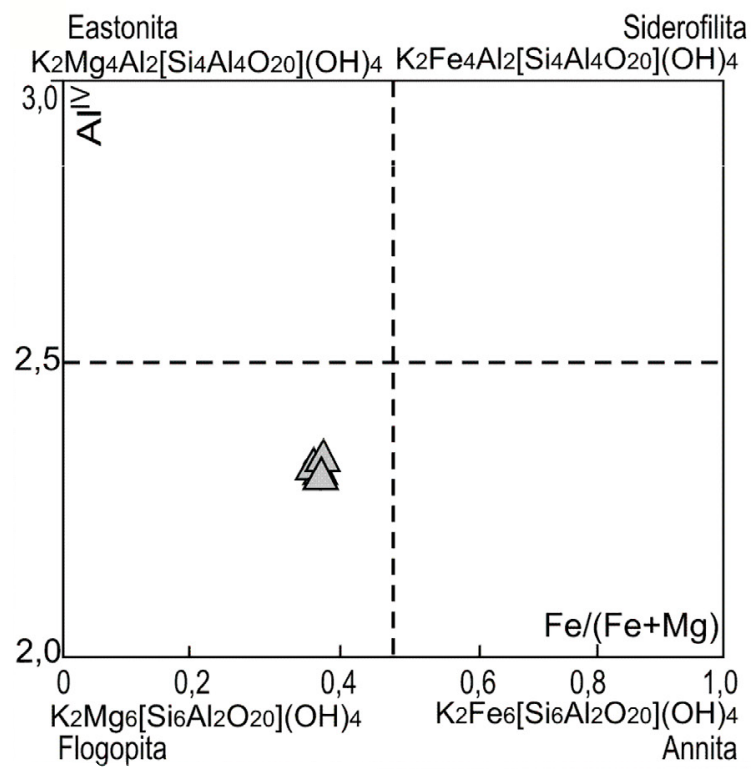

C

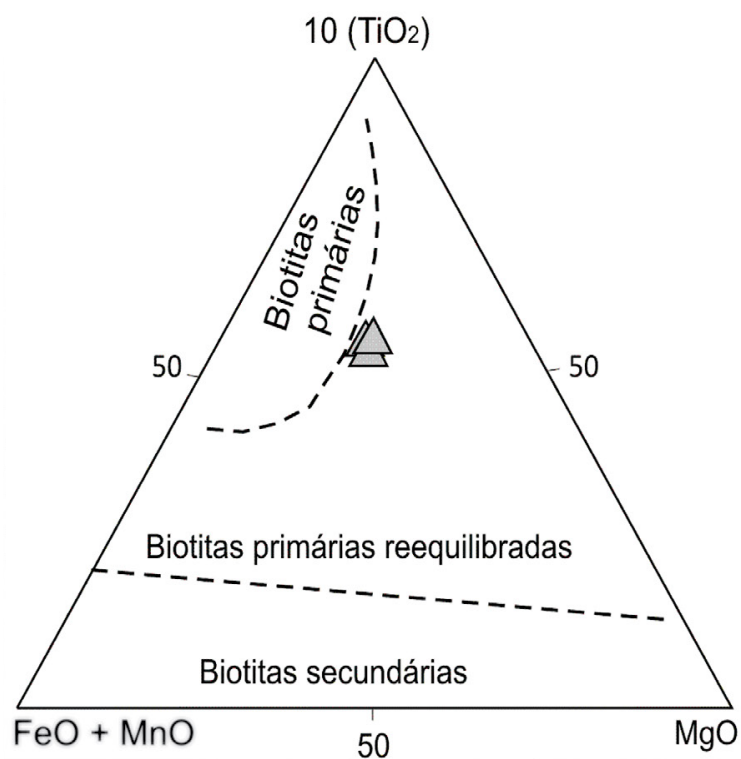

$\mathrm{T}\left({ }^{o} \mathrm{~K}\right)=1018 /\left[\ln \left(\mathrm{D}^{\mathrm{Zr} / \mathrm{magma}} / \mathrm{Zr}_{P T}\right)+1,16(\mathrm{M}-1)+1,48\right]$

Nessas equações, $\mathrm{D}^{\text {Zr/magma }}=476000$ (coeficiente de partição do zircônio em relação ao magma saturado em zircônio; Miller et al., 2003); T = temperatura absoluta (graus Kelvin); $\mathrm{Zr}_{R T}=$ concentração de $\mathrm{Zr}$ na amostra; e $\mathrm{M}$ = razão entre os cátions de acordo com a Equação 6:

$\mathrm{M}=[\mathrm{Na}+\mathrm{K}+2 \mathrm{Ca}] /(\mathrm{AlSi})$
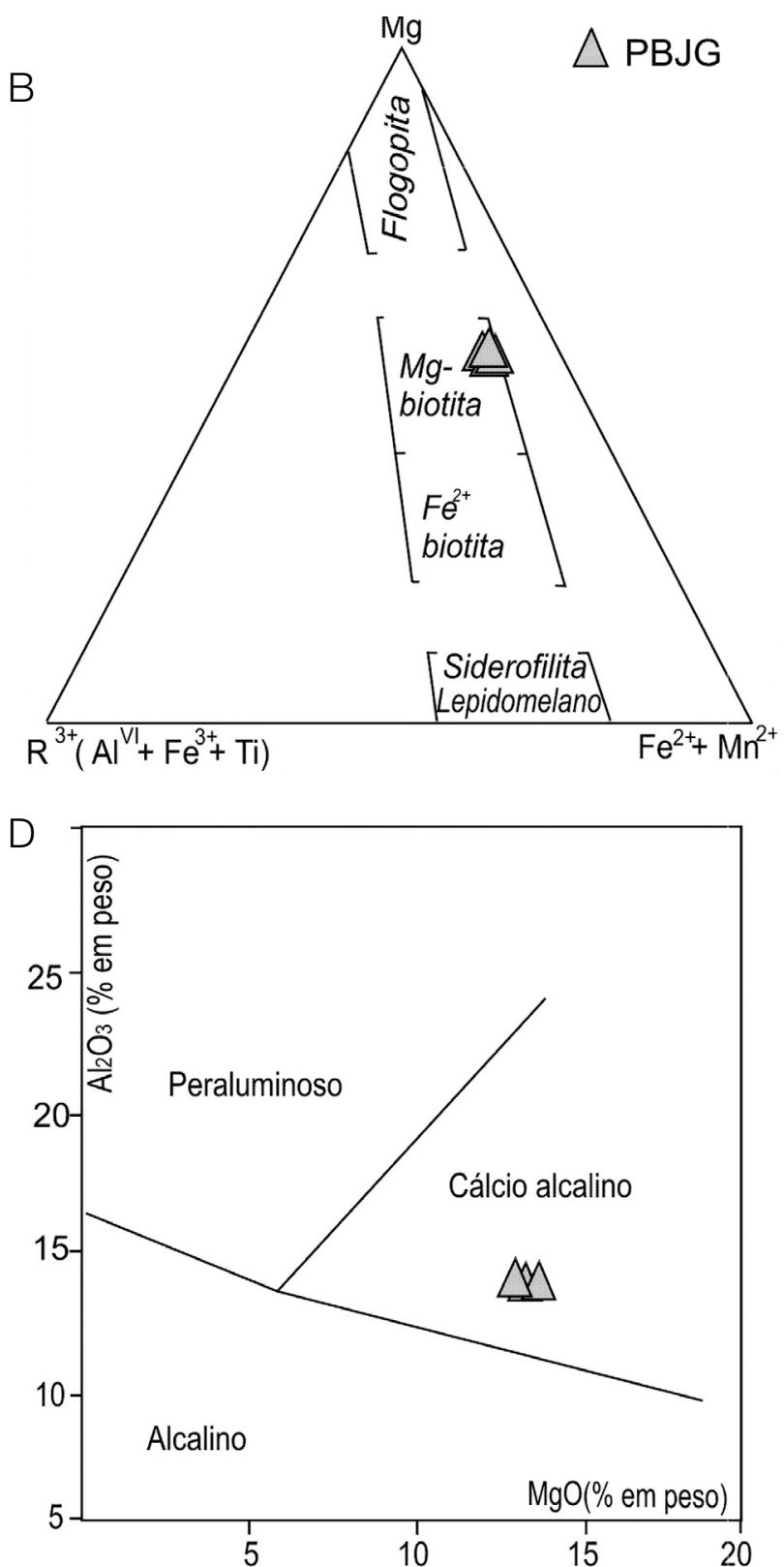

PBJG: Plutão Bom Jardim de Goiás.

Figura 6. Classificação química de biotitas do Plutão Bom Jardim de Goiás. (A) Diagrama de Speer (1984). (B) Diagrama de Foster (1960). (C) Discriminação entre biotitas primária e secundária em diagrama de Nachit et al. (2005). (D) Biotita e séries magmáticas segundo Abdel-Rahman (1994). 
As temperaturas obtidas com a Equação 4 foram, em média, $813^{\circ} \mathrm{C}$, e com a Equação $5,794^{\circ} \mathrm{C}$ (Tabela 7). Esses valores estão em conformidade com aqueles

Tabela 4. Análises de plagioclásio (calculado para 32 oxigênios) do Plutão Bom Jardim de Goiás (tonalito MK8), obtidas por microssonda eletrônica.

\begin{tabular}{|c|c|c|c|c|c|}
\hline Cristal & & 1 & & 2 & 3 \\
\hline $\mathrm{N}^{\circ}$ da análise & c & B & b & c & c \\
\hline Posição (P) & P-19 & P-20 & $P-21$ & $\mathrm{P}-22$ & P-23 \\
\hline $\mathrm{SiO}_{2}$ (\% peso) & 58,90 & 60,31 & 60,05 & 59,61 & 58,98 \\
\hline $\mathrm{TiO}_{2}^{2}$ & 0,01 & 0,01 & 0,03 & - & - \\
\hline $\mathrm{Al}_{2} \mathrm{O}_{3}$ & 25,68 & 24,14 & 24,86 & 24,88 & 25,55 \\
\hline $\mathrm{FeO}$ & 0,19 & 0,18 & 0,18 & 0,21 & 0,19 \\
\hline $\mathrm{MnO}$ & - & 0,04 & 0,10 & - & 0,06 \\
\hline $\mathrm{MgO}$ & - & - & 0,01 & - & - \\
\hline $\mathrm{CaO}$ & 7,59 & 5,97 & 6,36 & 6,57 & 7,25 \\
\hline $\mathrm{Na}_{2} \mathrm{O}$ & 6,88 & 7,64 & 7,53 & 6,85 & 7,09 \\
\hline $\mathrm{K}_{2} \mathrm{O}$ & 0,31 & 0,11 & 0,33 & 0,41 & 0,24 \\
\hline Total & 99,56 & 98,40 & 99,45 & 98,53 & 99,36 \\
\hline Si (pfu) & 10,57 & 10,88 & 10,76 & 10,76 & 10,60 \\
\hline $\mathrm{Al}$ & 5,43 & 5,13 & 5,25 & 5,29 & 5,41 \\
\hline $\mathrm{Ca}$ & 1,46 & 1,15 & 1,22 & 1,27 & 1,40 \\
\hline $\mathrm{Fe}$ & 0,03 & 0,03 & 0,03 & 0,03 & 0,03 \\
\hline $\mathrm{Na}$ & 2,39 & 2,67 & 2,62 & 2,40 & 2,47 \\
\hline $\mathrm{K}$ & 0,07 & 0,03 & 0,07 & 0,10 & 0,06 \\
\hline Soma-cátions & 19,95 & 19,90 & 19,96 & 19,84 & 19,96 \\
\hline An (\% molar) & 37,20 & 29,94 & 31,22 & 33,74 & 35,61 \\
\hline $\mathrm{Ab}$ (\% molar) & 60,99 & 69,39 & 66,89 & 63,72 & 62,98 \\
\hline Or (\%molar) & 1,81 & 0,67 & 1,90 & 2,53 & 1,41 \\
\hline
\end{tabular}

${ }^{*} \mathrm{C}$ : centro. b: borda.

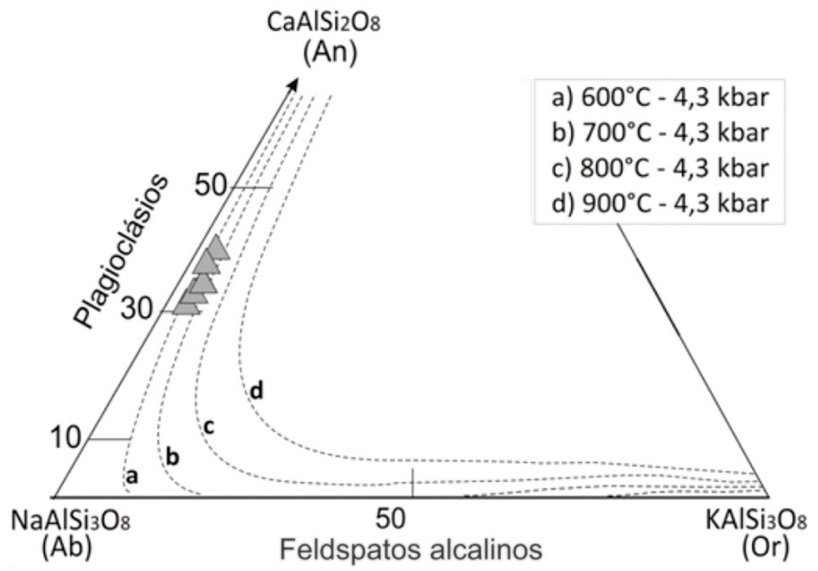

Figura 7. Composição de plagioclásios do Plutão Bom Jardim de Goiás no diagrama Or-Ab-An, comparados às isotermas calculadas no software SOLVCALC (Wen e Nekvasil, 1994) para 4,3 kbar, com base em Fuhrman e Lindsley (1988). demonstrados nos diagramas que relacionam a concentração de $\mathrm{Zr}$ (ppm) em rocha total ao índice $\mathrm{M}$ (Figuras 8 e 9).

Tabela 5. Química de minerais opacos (calculadas para 4 oxigênios) do Plutão Bom Jardim de Goiás, obtidas por microssonda eletrônica.

\begin{tabular}{|c|c|c|c|c|}
\hline Cristal & 1 & 2 & 3 & 4 \\
\hline $\mathrm{N}^{\circ}$ da análise & 10 & 11 & 12 & 15 \\
\hline Posição & $\mathrm{C}$ & c & C & c \\
\hline $\mathrm{TiO}_{2}(\%$ peso) & 0,03 & 0,01 & 0,04 & 0,00 \\
\hline $\mathrm{Al}_{2} \mathrm{O}_{3}$ & 0,10 & 0,06 & 0,05 & 0,04 \\
\hline $\mathrm{Fe}_{2} \mathrm{O}_{3}$ & 67,62 & 68,19 & 67,78 & 67,96 \\
\hline $\mathrm{FeO}$ & 30,49 & 30,59 & 30,57 & 30,61 \\
\hline $\mathrm{MnO}$ & 0,06 & 0,15 & 0,03 & 0,00 \\
\hline Total & 98,30 & 99,00 & 98,48 & 98,61 \\
\hline Si (pfu) & - & - & - & - \\
\hline $\mathrm{Al}$ & - & - & - & - \\
\hline $\mathrm{Ti}$ & - & - & - & - \\
\hline $\mathrm{Fe}^{3+}$ & 1,99 & 2,00 & 2,00 & 2,00 \\
\hline $\mathrm{Fe}^{2+}$ & 1,00 & 1,00 & 1,00 & 1,00 \\
\hline $\mathrm{Mn}$ & - & - & - & - \\
\hline Total & 3,00 & 3,00 & 3,00 & 3,00 \\
\hline
\end{tabular}

${ }^{*} \mathrm{C}$ : centro. b: borda.

Tabela 6. Síntese dos parâmetros intensivos de cristalização do Plutão Bom Jardim de Goiás, de acordo com geotermômetros e geobarômetros de diferentes autores.

\begin{tabular}{lcccc}
\hline $\begin{array}{l}\mathbf{N}^{\circ} \text { da análise } \\
\left(\mathrm{An}_{30 \%}\right)\end{array}$ & ${ }^{(1)} \mathbf{P}(\mathbf{k b a r})$ & ${ }^{(3)} \mathbf{T}\left({ }^{\circ} \mathbf{C}\right)$ & ${ }^{(2)} \mathbf{P}(\mathbf{k b a r})$ & ${ }^{(3)} \mathbf{T}\left({ }^{\circ} \mathbf{C}\right)$ \\
\hline 5 & 3,97 & 733 & 3,09 & 741 \\
6 & 4,42 & 747 & 3,15 & 759 \\
9 & 4,2 & 755 & 2,72 & 770 \\
13 & 4,06 & 692 & 3,87 & 693 \\
16 & 5,08 & 747 & 3,76 & 758 \\
17 & 4,06 & 732 & 3,19 & 740 \\
18 & 4,73 & 722 & 4,02 & 728 \\
\hline $\mathbf{N}^{\circ}$ da análise & & & & \\
$\left(\mathrm{An} \mathbf{n}_{37 \%}\right)$ & & & & \\
\hline 5 & 3,97 & 752 & 2,64 & 765 \\
6 & 4,42 & 768 & 2,55 & 786 \\
9 & 4,2 & 777 & 2,07 & 799 \\
13 & 4,06 & 709 & 3,62 & 712 \\
16 & 5,08 & 769 & 3,13 & 786 \\
17 & 4,06 & 752 & 2,74 & 763 \\
18 & 4,73 & 741 & 3,61 & 750 \\
\hline
\end{tabular}

(1)Schmidt (1992); (2)Anderson e Smith (1995), (3)Holland e Blundy (1994). 


\section{INTEGRAÇÃO DOS DADOS E DISCUSSÃO}

A paragênese mineral (andalusita + cordierita + silimanita) observada nas rochas encaixantes intrudidas pelo PBJG indica metamorfismo de baixa pressão na fácies anfibolito $(\mathrm{P}<4 \mathrm{kbar}$, $\mathrm{T}<600^{\circ} \mathrm{C}$ ). Desse modo, pode-se considerar que a colocação do magma se deu em crosta relativamente fria, após o pico do episódio tectono-metamórfico regional, possivelmente o evento Brasiliano. De acordo com os dados de química mineral aqui apresentados, as temperaturas de cristalização que melhor se adaptam a esse contexto são aquelas obtidas pelas interações das equações de Holland e Blundy (1994) e das pressões de Anderson e Smith (1995), em torno de 693 a $799^{\circ} \mathrm{C}$ para pressão da ordem de 2,1 a $4,0 \mathrm{kbar}$.

Segundo o geotermômetro de saturação em zircônio, as temperaturas mais próximas de liquidus foram estimadas em cerca de 813 e $794^{\circ} \mathrm{C}$ (Watson e Harrison, 1983; Boehnke et al., 2013), já a estimativa mínima da temperatura de soli$d u s$, obtida por meio da composição do plagioclásio e isotermas estabelecidas por Fuhrman e Lindsley (1988), entre 600 e $700^{\circ} \mathrm{C}$, considerando a pressão de 4,3 kbar. A $f \mathrm{O}_{2}$ exerce forte controle químico sobre as principais fases máficas de rochas graníticas (Anderson e Smith, 1995). As composições químicas de anfibólios e biotitas mostram baixas razões $\mathrm{Fe} /(\mathrm{Fe}+\mathrm{Mg})$, inferiores a 0,41. Quando relacionados ao conteúdo de $\mathrm{Al}^{I V}$ da hornblenda, esses valores indicam cristalização com elevada $f \mathrm{O}_{2}$ (Figura 9). Tal interpretação

Tabela 7. Temperatura de saturação de Zr calculada para composição química de rocha total de amostras do Plutão Bom Jardim de Goiás.

\begin{tabular}{llcccc}
\hline Litologia/amostra & $\begin{array}{c}\text { Zr } \\
(\mathbf{p p m})\end{array}$ & ${ }^{1} \mathbf{M}$ & ${ }^{1} \mathbf{T}^{\circ} \mathbf{C}$ & ${ }^{2} \mathbf{T}^{\circ} \mathbf{C}$ \\
\hline $\begin{array}{l}\text { Quartzo } \\
\text { monzodiorito }\end{array}$ & MK1B & 199 & 1,293 & 817 & 788 \\
\hline & MK8 & 173 & 1,287 & 805 & 787 \\
& MK15-A & 234 & 1,15 & 844 & 787 \\
& MK16-C & 200 & 1,33 & 815 & 795 \\
Tonalito & MK18 & 197 & 1,21 & 823 & 786 \\
& MK19-A & 95 & 1,834 & 717 & 814 \\
& MK19-B & 204 & 1,721 & 787 & 806 \\
& MK20 & 164 & 1,245 & 803 & 793 \\
& MK21 & 222 & 1,284 & 828 & 793 \\
& MK31 & 134 & 1,61 & 759 & 804 \\
\hline Granodiorito & MK1-A & 249 & 1,502 & 822 & 801 \\
& MK3-A & 385 & 1,099 & 899 & 786 \\
& MK13 & 203 & 1,283 & 820 & 794 \\
\hline
\end{tabular}

${ }^{1}$ Calculado de acordo com a Equação 4 de Watson e Harrison (1983); ${ }^{2}$ Calculado segundo a Equação 5 de Boehnke et al. (2013); ${ }^{1} \mathrm{M}=[\mathrm{Na}+\mathrm{K}+2 \mathrm{Ca}] /(\mathrm{AlSi})$.
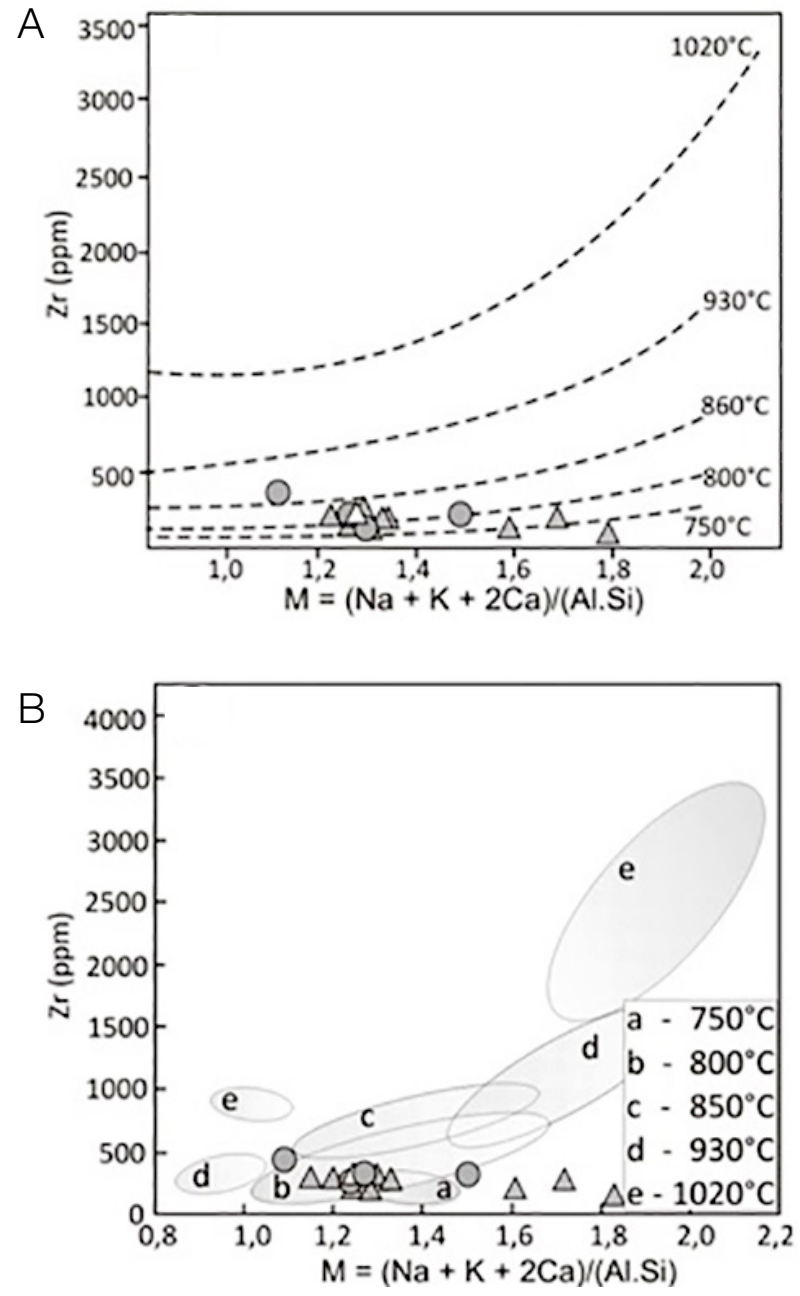

\section{$\triangle$ Quartzo monzodiorito $\triangle$ Tonalito $\bigcirc$ Granodiorito}

Figura 8. Diagrama Zr vs. M com isotermas definidas em (A) por Watson e Harrison (1983) e os campos de temperatura estabelecidos em (B) por Boehnke et al. (2013).

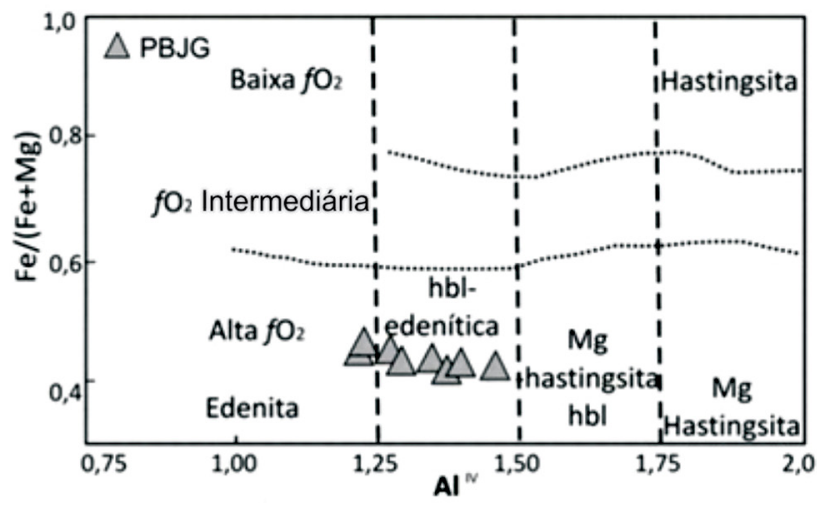

Figura 9. Diagrama relacionando a razão $\mathrm{Fe} /(\mathrm{Fe}+\mathrm{Mg})$ vs $\mathrm{Al}^{\mathrm{IV}}$ e $\mathrm{fO}_{2}$ de anfibólios (Anderson e Smith, 1995). 
é evidenciada pela paragênese magnetita + titanita, observada nas fácies intermediárias do PBJG.

A circulação de fluidos tardi a pós-magmáticos, provavelmente com certo conteúdo de $\mathrm{CO}_{2}$, teria sido responsável por carbonatação e saussuritização do plagioclásio. Na biotita, esses mesmos fluidos podem ter favorecido a substituição parcial por titanita, clorita e epídoto.

\section{CONCLUSÕES}

Com base no exposto, listam-se abaixo as principais conclusões deste trabalho:

- Os anfibólios do PBJG são edenita e Mg-hornblenda;

- A composição química dos cristais de biotita do PBJG (Mg-biotita) mostra enriquecimento na molécula de flogopita, com características de biotitas de magmas cálcio-alcalinos;

- No final da cristalização do PBJG, possivelmente em condições de subsolidus, houve a atuação de fluidos e vapores tardios contendo essencialmente $\mathrm{H}_{2} \mathrm{O}$ e $\mathrm{CO}_{2}$, o que favoreceu processos de alteração de fases prévias (biotita e feldspatos);

- Baixas razões $\mathrm{Fe} /(\mathrm{Fe}+\mathrm{Mg})$ de anfibólios e biotitas e assembleia mineral: quartzo + magnetita + titanita sugerem a prevalência de condições de $f \mathrm{O}_{2}$ elevada para o PBJG;

- A temperatura de cristalização inicial do PBJG, próxima ao liquidus foi estimada entre 813 e $794^{\circ} \mathrm{C}$, de acordo com geotermômetro de $\mathrm{Zr}$ ( $\mathrm{ppm}$ ) em rocha total;

- A composição química do par anfibólio-plagioclásio permitiu determinar a temperatura de cristalização entre 693 e $799^{\circ} \mathrm{C}$;

- A estimativa mínima da temperatura de solidus do PBJG foi estabelecida entre $600 \mathrm{e} 700^{\circ} \mathrm{C}$, relacionando a composição do plagioclásio com isotermas de Fuhrman e Lindsley (1988);

- De acordo com geobarômetros empregados, aliados à análise da paragênese mineral, estima-se que a melhor pressão de cristalização do PBJG ocorreu entre 2,1 e 4,0 kbar.

\section{AGRADECIMENTOS}

Os autores agradecem ao Programa de Pós-Graduação em Geodinâmica e Geofísica da Universidade Federal do Rio Grande do Norte (PPGG/UFRN) e ao Departamento de Geologia da UFRN, onde foram tratados os dados; ao Programa Núcleos de Excelência (PRONEX), do Conselho Nacional de Desenvolvimento Científico e Tecnológico (CNPq), coordenado pela Profa. Dra. Rúbia Ribeiro Viana, do Departamento de Recursos Minerais da Universidade Federal de Mato Grosso (DRM/UFMT); e à Coordenação de Aperfeiçoamento de Pessoal de Nível Superior (CAPES), por concessão de bolsa de mestrado para KTOC.

\section{REFERÊNCIAS}

Abbott Jr., R. N., Clarke, D. B. (1979). Hypothetical liquidus relationships in the subsystem $\mathrm{Al}_{2} \mathrm{O}_{3}-\mathrm{FeO}-\mathrm{MgO}$ projected from quartz, alkali feldspar and plagioclase for $\mathrm{a}\left(\mathrm{H}_{2} \mathrm{O}\right) \leq 1$. Canadian Mineralogist, 17, 549-560.

Abdel-Rahman, A. M. (1994). Nature of biotites from alkaline, calc-alkaline, and peraluminous magmas. Journal of Petrology, 35, 525-541.

Almeida, F. F. M., Brito Neves, B. B., Fuck, R. (1981). Brazilian structural provinces: an introduction. Earth Science Reviews, 17, 1-29.

ALS Minerals. (2014). Geochemistry downloads ME-MS81 Lithogeochemistry. Acesso em 10 de janeiro de 2014, <https:// www.alsglobal.com/\#services-section/services-detail>.

Anderson, J. L., Smith, D. R. (1995). The effects of temperature and $f \mathrm{O} 2$ on the $\mathrm{Al}$-in-hornblende barometer. American Mineralogist, 80, 549-559.

Boehnke, P., Watson E. B., Trail D., Harrison T. M., Scmitt A. K. (2013). Zircon saturation re-revisited. Chemical Geology, 351, 324-334.

Carmichael, I. S. E. (1967). The iron-titanium oxides of salic volcanic rocks and their associated ferromagnesian silicates. Contributions to Mineralogy and Petrology, 14(1), 36-64.

Coimbra, K. T. O. (2015). Petrologia do plutão Bom Jardim de Goiás: Implicação para evolução geodinâmica da Província Tocantins. Dissertação (Mestrado). Programa de Pós-Graduação de Geodinâmica e Geofísica, Centro de Ciências Exatas e da Terra, Universidade Federal do Rio Grande do Norte.

Deer, W. A., Howie, R., Zussman, J. (1992). An introduction to the Rock-Forming Minerals ( ${ }^{\text {nd }}$ ed., 298p). New York: Prentice Hall.

Foster, M. D. (1960). Interpretation of the composition of trioctahedral micas. US Geological Survey, Professional Papers, 354, 1-49.

Fuhrman, M. L., Lindsley, D. H. (1988). Ternary-feldspar modeling and thermometry. American Mineralogist, 73, 201-215.

Hammarstrom, J. M., Zen, E. (1986). Aluminum in hornblende: An empirical igneous geobarometer. American Mineralogist, 7(1), 1297-1313. 
Holland, T., Blundy, J. (1994). Non-ideal interactions in calcic amphiboles and their bearing on amphibole-plagioclase thermometry. Contributions to Mineralogy and Petrology, $116,433-447$.

Hossain, I., Tsunogae, T. (2014). Crystallization Conditions and Petrogenesis of the Paleoproterozoic Basement Rocks in Bangladesh: An Evaluation of Biotite and Coexisting Amphibole Mineral Chemistry. Journal of Earth Science, 25(1), 87-97.

Lamarão, C. N., Dall'Agnol, R. (2004). Química mineral de anfibólios e biotitas e condições de cristalização de granitóides paleoproterozoicos da região de Vila Riozinho, Província Aurífera do Tapajós, Cráton Amazônico. Revista Brasileira de Geociências, 34(1), 95-108.

Lameyre, J., Bowden, P. (1982). Plutonic rock type series: discrimination of various granitoid series and related rocks. Journal of Volcanology and Geothermal Research, 14, 169-186.

Laux, J. H., Pimentel, M. M., Dantas, E. L., Armstrong, R., Armele, A., Nilson, A. A. (2004). Mafic magmatism associated with the Goiás Magnatic Arc in the Anicuns region, Goiás central Brazil: Sm-Nd isotopes and new ID-TIMS and SHRIMP U-Pb data. Journal of South American Earth Sciences, 16, 599-614.

Leake, B. E., Wooley, A. R., Arps, C. E. S., Birch, W. D., Gilbert, M. C., Grice, J. D., Hawthorne, F. C., Kato, A., Kisch, H. J., Krivovichev, V. G., Linthout, K., Laird, J., Mandarino, J. A., Maresch, W. V., Nickel, E. H., Schumacher, J., Smith, J. C., Stephenson, N. C. N., Ungaretti, L., Whittaker, E. J. W., Youzhi, G. (1997). Nomenclature of Amphiboles: Report of the Subcommittee on Amphiboles of the International Mineralogical Association Commission on New Minerals and Mineral Names. Mineralogical Magazine, 61, 295-321.

Miller, C. F., McDowell, S. M., Mapes, R. W. (2003). Hot and cold granites? Implications of zircon saturation temperatures and preservation of inheritance. Geological Society of America, 31, 529-553.

Nachit, H., Ibhi, A., El Hassan, A., Bem, M. O. (2005). Discrimination between primary magmatic biotites, reequilibrated biotites and neoformed biotites. Comptes Rendus Géoscience, 337, 1415-1420.

Pimentel, M. M., Fuck, R. A., Botelho, N. F. (1999). Granites and the geodynamic history of the neoproterozoic Brasília belt, Central Brazil: a review. Lithos, 46, 463-483.

Pimentel, M. M., Fuck, R. A., Gioia, S. M. C. L. (2000). The Neoproterozoic Goiás Magmatic Arc, central Brazil: a review and new Sm-Nd data. Revista Brasileira de Geociências, 30, 35-39.

Pimentel, M. M., Heaman, L., Fuck, R. A. (1991). U-Pb zircon and sphene geochronology of Late Proterozoic volcanic arc rocks units from southwestern Goiás, central Brazil. Journal of South American Earth Science, 4, 329-339.

Pimentel, M. M., Jost, H., Fuck, R. A. (2004). O embasamento da Faixa Brasília e o Arco Magmático de Goiás. In: V. Mantesso Neto, A. Bartorelli, C. D. R. Carneiro, B. B. Brito Neves (Eds.), Geologia do Continente Sul-Americano: Evolução da Obra de Fernando Flávio Marques de Almeida (Cap. 21, 355-368). São Paulo: Becca.

Pimentel, M. M., Reinhardt, A., Fuck, R. A., Silva, J. H. D. R. (1996). Dados Rb-Sr e Sm-Nd da região de JussaraGoiás-Mossâmedes (GO), e o limite entre terrenos antigos do Maciço de Goiás e o Arco Magmático de Goiás. Revista Brasileira de Geociências, 26, 61-70.

Schmidt, M. W. (1992). Amphibole composition in tonalites as a function of pressure: an experimental calibration of the Al-in-hornblende barometer. Contributions to Mineralogy and Petrolology, 110, 304-310.

Speer, J. A. (1984). Micas in igneous rocks. In: S. W. Bailey. Reviews in Mineralogy. Blacksburg, Mineralogical Society of America, 13, 299-356.

Streckeisen, A. L. (1976). To each plutonic rocks its proper name. Earth Science Reviews, 12, 1-33.

Viana, M. G., Pimentel, M. M., Whitehouse, J., Fuck, R. A., Machado, N. (1995). O Arco Magmático de Mara Rosa, Goiás: Geoquímica e geocronologia e suas implicações regionais. Revista Brasileira de Geociências, 25, 111-123.

Vilalva, F. C. J., Vlach, S. R. F. (2014). Geology, petrography and geochemistry of the A-type granites from the Morro Redondo Complex (PR-SC), southern Brazil, Graciosa Province. Anais da Academia Brasileira de Ciências, 86(1), 85-116.

Watson, E. B., Harrison, T. M. (1983). Zircon saturation revisited temperature and composition effects in a variety of crustal magma types. Earth and Planetary Science Letters, 64, 295-304.

Wen, S., Nekvasil, H. (1994). SOLVALC: An interactive graphics program package for calculating the ternary feldspar solvus and for two-feldspar geothermometry. Computers and Geosciences, 20, 1025-1040. 